\title{
Hydrogen bonding and secondary interactions in halogenated complexes
}

Francoise M. Amombo Noa ${ }^{1}$, Susan A. Bourne ${ }^{1}$, Luigi R. Nassimbeni ${ }^{1}$

${ }^{1}$ University Of Cape Town, Department Of Chemistry, Cape Town, South Africa E-mail: noa.mystere@gmail.com

Halogenated compounds which contain both hydroxyl group and electronegative species $(\mathrm{Cl}, \mathrm{Br}$ and $\mathrm{I})$ have been synthesized and characterized using single x-ray diffraction, thermal analysis, solid-vapor kinetics of formation, Hirshfeld surface analysis and IR spectroscopy. In some of the complexes, a competition between halogen and hydrogen bonding was conducted and in all cases the hydrogen bonding motif (Host) $\mathrm{O}-\mathrm{H} \cdots \mathrm{O}$ (Host)- $\mathrm{H} \cdots \mathrm{N}$ (Guest) was predominated while the halogen ...halogen interactions were of secondary importance on the crystal structure packings. Complexes with NiI2 formed ionic compounds, forming I- salts which yielded tri-iodide anions on the addition of I2. Halogen bond in this research has played an important role in binding and recognition of the obtained crystal structures. Figure 1, illustrates the hydrogen bonding and halogen bonding in the halogenated complexes

[1] Noa. A. F. M. et al. (2016) Crystal Growth Des. 16, 4765 - 4771.
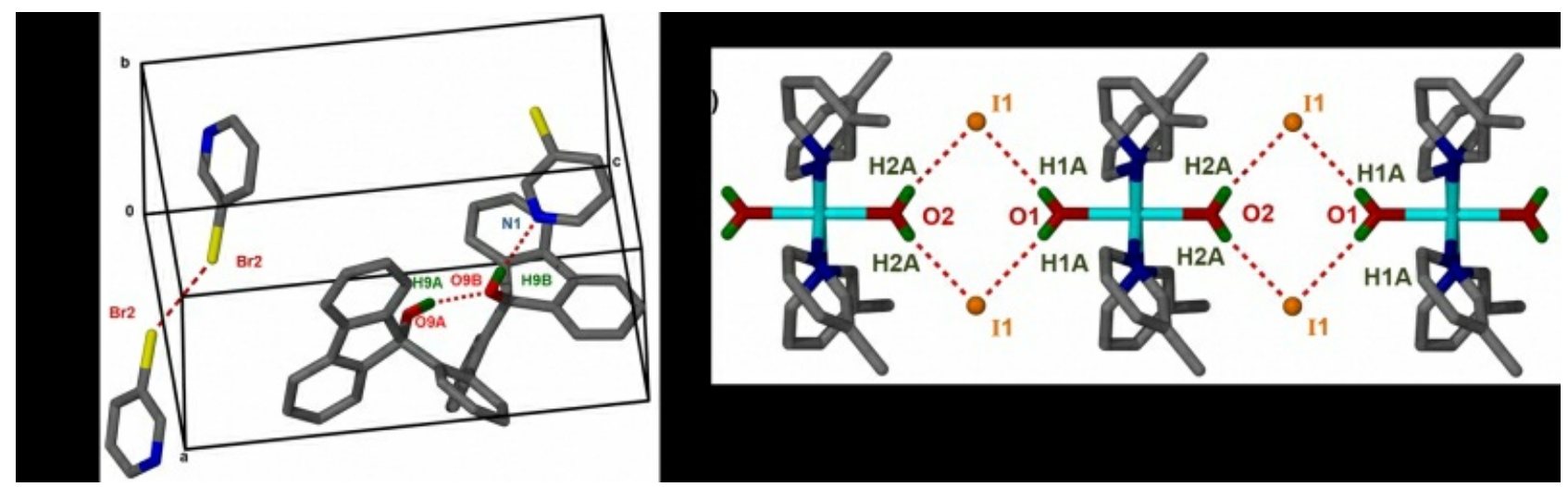

Keywords: Hydrogen bond, halogen bond, halogenated complexes 